TITLE:

\title{
Expectant management of a herniated amniotic sac presenting as silent uterine rupture: a case report and literature review.
}

\section{$\operatorname{AUTHOR(S):~}$}

lemura, Asako; Kondoh, Eiji; Kawasaki, Kaoru; Fujita, Kohei; Ueda, Akihiko; Mogami, Haruta; Baba, Tsukasa; Konishi, Ikuo

\section{CITATION:}

lemura, Asako ...[et al]. Expectant management of a herniated amniotic sac presenting as silent uterine rupture: a case report and literature review.. The journal of maternal-fetal \& neonatal medicine 2014, 28(1): 106-112

\section{ISSUE DATE:}

2014-04-09

URL:

http://hdl.handle.net/2433/199654

\section{RIGHT:}

This is an Accepted Manuscript of an article published by Taylor \& Francis in The Journal of Maternal-Fetal \& Neonatal Medicine on 09 Apr 2014, available online: http://www.tandfonline.com/10.3109/14767058.2014.900533.; This is not the published version. Please cite only the published version.; この論文は出版社版でありません。引用の際には出版社版 をご確認ご利用ください。 


\section{Expectant management of a herniated amniotic sac presenting as silent uterine rupture: a case report and literature review}

Asako IEMURA, MD; Eiji KONDOH, MD, PhD*; Kaoru KAWASAKI, MD; Kohei FUJITA, MD, PhD; Akihiko UEDA, MD; Haruta MOGAMI, MD, PhD; Tsukasa BABA, MD, PhD; Ikuo KONISHI, MD, PhD

Department of Gynaecology and Obstetrics, Kyoto University, Kyoto, Japan

*Corresponding author address:

Department of Gynaecology and Obstetrics, Kyoto University

54 Shogoin Kawahara-cho, Sakyo-ku, Kyoto 606-8507, Japan

Tel: +81-75-751-3269

Fax: +81-75-761-3967

E- mail: kondo@kuhp.kyoto-u.ac.jp

\section{Short title}

Uterine rupture

\section{Keywords}

Diffuse uterine leiomyomatosis, conservative management, pregnancy, uterine dehiscence, uterine rupture 


\begin{abstract}
Foetal membranes bulging into the abdominal cavity is a unique initial manifestation of silent or complete uterine rupture during pregnancy. Since silent uterine rupture has potential risk for complete uterine rupture, which leads to acute life-threatening complications for both the mother and baby, it is difficult to determine whether to manage expectantly or surgically, including repair of the uterine wall or termination of the pregnancy, especially in the early second trimester.
\end{abstract} We present here a case of a herniated amniotic sac with overstretched uterine wall of the fundus presenting as silent uterine rupture, which was incidentally detected on routine ultrasonography at 18 weeks' gestation in a 38-year-old primigravida with a history of myomectomy for diffuse uterine leiomyomatosis. Magnetic resonance imaging examination revealed that the myometrium thickness was fully maintained at the site of the foetal membranes ballooning. The pregnancy was therefore managed expectantly and continued to successful delivery at 30 weeks' gestation. The precise assessment of the uterine wall may be essential to manage a herniated amniotic sac presenting as silent uterine rupture and to optimise the outcome of the pregnancy. We review all cases of a herniated amniotic sac out of focally 
overstretched uterine wall before 34 weeks' gestation. (200/200 words) 


\section{Introduction}

A herniated amniotic sac into the abdominal cavity is a unique initial manifestation of silent or complete uterine rupture during pregnancy [1-23]. Silent uterine rupture is relatively asymptomatic, but has the potential risk for complete uterine rupture $[7,9,15,17,19]$, which leads to acute life-threatening complications for both the mother and baby. To date, there is no consensus on whether to adopt expectant or surgical management for pregnancies presenting with amniotic sac protrusion out of the uterine wall, especially in the first and early second trimesters.

In order to determine the optimal management of seemingly silent uterine rupture with a herniated amniotic sac, it is important to conduct accurate assessment of the surrounding myometrium thickness and how the uterine wall changes as the pregnancy advances. We describe here a case of a large protruding amniotic sac into the abdominal cavity in the uterine fundus, which was incidentally detected on routine ultrasonography at 18 weeks of gestation in a primigravida with diffuse uterine leiomyomatosis following myomectomy. The disproportionately overextended uterine wall was serially evaluated using magnetic resonance imaging (MRI). The pregnancy succeeded in deferring the delivery of the foetus until 30 
weeks' gestation. We also review all cases of a herniated amniotic sac out of the uterine wall before 34 weeks' gestation in the English literature. This article sheds light on the pathogenesis and management of a herniated amniotic sac presenting as silent uterine rupture in pregnancy. 


\section{Case}

A 38-year-old primigravida was transferred to our hospital for evaluation

of a large amniotic sac that appeared to be protruding from the fundus of the uterus at

18 weeks' gestation. She had been suffering from hypermenorrhoea due to diffuse

uterine leiomyomatosis (Supplementary Figure 1A). Two years prior to the current

pregnancy, which was conceived by in vitro fertilisation, the patient had a history of abdominal enucleation of 64 fibroids through a vertical incision from the anterior to posterior wall via uterine fundus in our hospital (Supplementary Figure 1B). Her prenatal course was uncomplicated. Regular check-ups revealed no abnormal findings other than multiple fibroids. At 17 weeks' gestation, her fundal height was $17 \mathrm{~cm}$, and the uterine cervix was $3 \mathrm{~cm}$ in length. Upon admission, she remained asymptomatic, and her vital signs and blood tests were unremarkable. The fundal height was $26 \mathrm{~cm}$, and ultrasound examination showed that a large herniated amniotic sac measuring $70 \times 45 \mathrm{~mm}$ was extending into the maternal abdominal cavity at the uterine fundus (Figure 1A). Ultrasonography demonstrated a viable appropriately grown foetus in breech presentation with seemingly decreased amniotic fluid volume (Figure 1A). The uterine cervix was dilated to $2 \mathrm{~cm}$, and 7 
$\mathrm{mm}$ in length with funnelling on transvaginal ultrasonography (Figure 1A). Although the herniated amniotic sac appeared to be covered by a relatively thick rim of myometrium externally, it was difficult to evaluate the thickness of the uterine fundal myometrium on ultrasound assessment alone. An MRI scan was performed and showed that the ballooning amniotic sac was covered with a myometrial rim with a thickness of at least $5 \mathrm{~mm}$ (Figure 1B). The patient had no pain, and the foetal status was not ominous. A panel of experts from obstetrics, gynaecology and radiology discussed the case extensively and concluded that surgical intervention was not likely to be required for the patient.

The patient was informed of the potential risks of foetal and maternal mortality and morbidity due to spontaneous uterine rupture during pregnancy. Because the patient and her family strongly wished to continue the pregnancy, expectant management was conducted. A Shirodkar cerclage was performed to prevent preterm delivery on the day of admission. Bed rest and tocolytic therapy were initiated. The foetal arm and a loop of cord were found to have moved in and out of the herniated amniotic sac on occasion. The patient remained asymptomatic with reassuring foetal status and appropriate foetal growth. Daily ultrasound and 
monthly MRI examinations demonstrated that the peripheral uterine wall covering the protruding amniotic sac was relatively stable with regard to thickness $(2.6 \mathrm{~mm})$ (Figure 1C, D). In contrast, the lower uterine segment was unexpectedly fully formed as early as 26 weeks' gestation (Figure 1D, E), and was further overextended at 29 weeks' gestation (Figure 1 F, G). Moreover, the patient started to experience a vague lower abdominal discomfort above the pubis. Caesarean section was therefore carried out, and a healthy male baby weighing $1367 \mathrm{~g}$ was delivered at 30 weeks. At laparotomy, the lower segment of the uterus was found to be well-formed and extremely thin for the gestational age (Figure 2A). After manual removal of the placenta, subsequent exploration of the uterus failed to detect the site of overstretched myometrium; the appearance and direct palpation of the uterine fundus was normal except for the vertical midline hollow traces of a previous uterine incision for myomectomy (Figure 2A). Therefore, repair of the uterine wall of the fundus was not conducted. The patient had an uncomplicated postoperative course, and the baby was discharged home in a good condition 58 days after birth. A follow-up MRI examination revealed a relatively thin myometrium of the uterine fundus compared to other parts of the uterine wall three months postpartum (Figure 
2B). The patient was counselled extensively about the risks to future pregnancies.

\section{Discussion}

A herniated amniotic sac into the abdominal cavity is strongly suggestive of

imminent uterine rupture [1-23]. However, uterine rupture does not always occur immediately after sonographic detection of extrusion of the amniotic sac. To date, there have been 24 reports of foetal membranes ballooning through focally overstretched uterine walls, which occurred before 34 weeks' gestation (Table 1). A total of 16 cases (surgical group) underwent surgical intervention, including termination of the pregnancy and repair of uterine wall at $23.1 \pm 7.7$ weeks of gestation [8-23]. In contrast, eight cases (expectant group) were managed expectantly (initial manifestation at $22.0 \pm 6.9$ weeks of gestation), and the latency periods (interval between diagnosis and delivery) were $9.0 \pm 7.2$ weeks [1-7]. Although all cases in the expectant group underwent caesarean section prior to full-term due to worsening abdominal pain, abnormal foetal heart rate patterns, or labour onset, the mothers all gave birth to healthy babies. The current case also succeeded in deferring the delivery of the foetus for 12 weeks. Thus, these findings suggest that 
conservative treatment options can be considered for cases with a herniated amniotic sac presenting as silent uterine rupture.

The optimal management for cases with a herniated amniotic sac has yet to be defined, especially in the first and early second trimesters. The management of silent uterine rupture will depend on the gestational age, the degree of severity of abdominal pain, and foetal status. A caesarean delivery should be performed if the foetus is mature enough to survive outside the uterus. However, 17 (70.8\%) of the 24 cases in the control and expectant groups presented the initial manifestation of a herniated amniotic sac in the first and the second trimesters. To date, its influence on pregnancy has not been fully clarified when a patient is asymptomatic or shows temporary abdominal pain that is not accompanied with foetal distress. If a patient and her partner strongly wish to continue with the pregnancy, they must be provided with an extensive review of the potential risks for expectant management, including subsequent uterine rupture [7], placenta accreta [1,5], hysterectomy [1,5], and preterm birth [1-7].

In pregnancies complicated with a herniated amniotic sac, it is important to discriminate cases that require surgical intervention from those that can be managed 
expectantly. Currently, there are no established methods to predict uterine rupture.

Abdominal pain or discomfort may be the typical symptoms for imminent uterine rupture, but seven of the eight cases in the expectant group experienced abdominal pain at diagnosis, suggesting that the presence of the symptom alone cannot exclude the possibility of successful expectant management. Although several studies have shown that ultrasonographic assessment of the lower uterine segment close to term can predict uterine scar rupture when attempting vaginal birth after a previous caesarean section [24], no cut-off values for myometrium thickness exist for the prediction of spontaneous uterine rupture in cases of a herniated amniotic sac in pregnancy. Moreover, as shown in the current case, it is sometimes difficult to evaluate the thinning of the fundal myometrium accurately due to adjacent intestinal gas and alignment of the ultrasound beam parallel to the uterine fundal wall. Ultrasound evaluation of a fundal or posterior wall surrounding amniotic sac protrusion appears to be of limited value. Indeed, we initially considered operative repair of the uterine wall in the present case, but MRI findings provided precise information regarding the degree of overstretched myometrium thickness overlying the foetal membranes ballooning. We still had anxiety of uterine rupture throughout 
the follow up period since there has been no cut-off value for myometrium thickness for the prediction of spontaneous uterine rupture in cases of a herniated amniotic sac in pregnancy. So, serial (monthly) assessment of myometrial thickness using MRI was one of the key factors that made the expectant management possible. The MRI examination showed that the manifestation of a herniated amniotic sac did not always accompany thin myometrium surrounding it, indicating that MRI is a useful modality for determining whether or not surgical intervention is mandatory. Collectively, it may be said that expectant management is possible in a selected patient who is nearly asymptomatic and whose myometrial thickness is relatively thick, even at the thinnest portion surrounding a herniated amniotic sac.

A herniated amniotic sac mostly occurs in pregnancies with a history of caesarean delivery $(n=11)$, instrumental perforation $(n=5)$, or myomectomy $(n=2)$ and in twin pregnancies $(n=3)$. Therefore, the possible cause of a herniated amniotic sac is attributed to decreased elasticity in focal sites of myometrium scar tissue or excessive intrauterine pressure. This type of sonographic manifestation of silent uterine rupture has also been described as uterine dehiscence or uterine rupture. Uterine dehiscence, defined as separation of a prior uterine scar not extending to the 
serosa, is often used to describe a herniated amniotic sac with focally overstretched uterine wall $[4,5,7,10,11,14,16,20,21]$. However, extensive review of the literature does not provide obvious evidence that separation of a pre-existing scar does occur during pregnancy in cases presenting with a herniated amniotic sac. The present case showed that the peripheral myometrium thickness of the herniated amniotic sac was maintained during pregnancy, and a follow-up MRI examination three months postpartum demonstrated that there was no apparent separation at the fundus of the uterus. We therefore do not use the term "uterine dehiscence" in the current manuscript. Moreover, "uterine rupture" is sometimes used to describe a herniated amniotic sac in the reviewed articles [2,3], because the distinction between silent uterine rupture and complete uterine rupture is not always clear by sonography alone. Among the eight women in the expectant management group, there was one case who resulted in complete uterine rupture [7], while the rest of them required caesarean section due to potential uterine rupture [1-6] at $31.1 \pm 2.4$ weeks of gestation. Therefore, we should bear in mind that cases presenting with a herniated amniotic sac are at high risk for spontaneous uterine rupture in the early third trimester, regardless of the underlying causes or the different terminology that 
authors may have used.

The present case is characterised by numerous fibroids disproportionately located in the uterine wall. Bilateral sides of the uterine musculature were less likely to be stretched well due to numerous fibroids and may enhance intrauterine pressure, leading to the cervical dilatation, the formation of a herniated amniotic sac at the uterine fundus, and a subsequently overstretched lower uterine segment, which indicates the strong compensatory ability of the pregnant uterus. Although two patients with diffuse uterine leiomyomatosis had successful pregnancies following the same surgical procedure as the current case in our hospital, and encountered no complications during pregnancy [25], the present case suggests that pregnancy with diffuse uterine leiomyomatosis or diffuse adenomyosis may increase the risk of silent uterine rupture with a herniated amniotic sac due to reduction of the ability to stretch the uterine wall. Intriguingly, a herniated amniotic sac was observed at the fundus of the uterus in 13 of 24 cases (54.2\%). The high incidence of overstretched uterine fundus is probably because the long axis of the foetus is parallel to the long axis of the uterus, and more force may be imposed towards the axis, uterine cervix and fundus. 
In conclusion, a pregnancy presenting with a herniated amniotic sac at the

uterine fundus in the early second trimester was expectantly managed and continued to successful delivery at 30 weeks' gestation. The use of MRI aided the understanding of the spatiotemporal changes in the herniated amniotic sac and the focally overstretched uterine wall. The precise assessment of the uterine wall may be essential for managing a herniated amniotic sac presenting as silent uterine rupture and to optimise the outcome of the pregnancy.

\section{Acknowledgements}

N/A

\section{Disclosure of Interests}

The authors report no conflict of interest. 


\section{References}

[1] Deka D, Bahadur A, Dadhwal V, Gurunath S, Vaid A. Successful outcome in pregnancy complicated by prior uterine rupture: a report of two cases. Arch Gynecol Obstet 2011; 283 (Suppl 1): 45-8.

[2] Oyelese Y, Tchabo JG, Chapin B, Nair A, Hanson P, McLaren R. Conservative management of uterine rupture diagnosed prenatally on the basis of sonography. $J$ Ultrasound Med 2003; 22: 977-80.

[3] Cotton DB. Infant survival with prolonged uterine rupture. Am J Obstet Gynecol 1982; 142: 1059-60.

[4] Hamar BD, Levine D, Katz NL, Lim KH. Expectant management of uterine dehiscence in the second trimester of pregnancy. Obstet Gynecol 2003; 102: 1139-42.

[5] Hunter TJ, Maouris P, Dickinson JE. Prenatal detection and conservative management of a partial fundal uterine dehiscence. Fetal Diagn Ther 2009; 25: 123-6. 
[6] Taipale P, Karhumaa J, Penttinen J. Two- and three-dimensional sonographic diagnosis of incomplete uterine scar rupture during pregnancy. Ultrasound Obstet Gynecol 2005; 25: 418-9.

[7] Rabinowitz R, Samueloff A, Sapirstein E, Shen O. Expectant management of foetal arm extruding through a large uterine dehiscence following sonographic diagnosis at 27 weeks of gestation. Ultrasound Obstet Gynecol 2006; 28: 235-7.

2002; 17: 2180-2.

[8] Cheng PJ, Chueh HY, Soong YK. Sonographic diagnosis of a uterine defect in a pregnancy at 6 weeks' gestation with a history of curettage. Ultrasound Obstet Gynecol 2003; 21: 501-3.

[9] Liao CY, Ding DC.J. Repair of uterine rupture in twin gestation after laparoscopic cornual resection. Minim Invasive Gynecol 2009; 16: 493-5.

[10] Hamrick-Turner JE, Cranston PE, Lantrip BS. Gravid uterine dehiscence: MR findings. Abdom Imaging 1995; 20: 486-8.

[11] Zuckerwise LC, Cakmak H, Sfakianaki AK. Uterine dehiscence in early second trimester. Obstet Gynecol 2011; 118: 497-500.

[12] Fujii T, Kozuma S, Unno N, Kuwabara Y, Taketani Y. Successful pregnancy 
following antenatal closure of uterine wall defect. Int J Gynaecol Obstet 2000; 68:

261-2.

[13] Chou MM, Hwang JI, Tseng JJ, Chen WC, Hung SW, Ho ES. Diagnosis of an asymptomatic uterine rupture in a twin pregnancy with four-dimensional ultrasound examination and magnetic resonance imaging. Ultrasound Obstet Gynecol 2007; 30: 364-6.

[14] Gorthi S, Simpson NA, Lodge V, Dunham RJ, Lane G. Management of asymptomatic mid-trimester lower segment scar dehiscence. Eur J Obstet Gynecol Reprod Biol 2009; 147: 241-2.

[15] Jo YS, Kim MJ, Lee GS, Kim SJ. A large amniocele with protruded umbilical cord diagnosed by 3D ultrasound. Int J Med Sci 2012; 9: 387-90.

[16] Youngs DJ, Praska KA, Harms RW. Prenatal sonographic detection of uterine dehiscence. J Diagn Med Sonogr 2004; 20: 418-421.

[17] Chen FP. Term delivery after repair of a uterine rupture during the second trimester in a previously unscarred uterus: a case report. J Reprod Med 2007; 52: 981-3.

[18] Kushnir O, Tamarkin M, Barkai G, Mashiach S, Izquierdo LA, Shalev J. 
Extrauterine amniotic sac (amniocele). Clinical workup in a case of silent uterine rupture. J Ultrasound Med 1990; 9:367-9.

[19] van Alphen M, van Vugt JM, Hummel P, van Geijn HP. Recurrent uterine rupture diagnosed by ultrasound. Ultrasound Obstet Gynecol 1995; 5: 419-21.

[20] Hasbargen U, Summerer-Moustaki M, Hillemanns P, Scheidler J, Kimmig R, Hepp H. Uterine dehiscence in a nullipara, diagnosed by MRI, following use of unipolar electrocautery during laparoscopic myomectomy: Case report. Hum Reprod [21] Avrech OM, Weinraub Z, Herman A, et al. Ultrasonic antepartum assessment of a classical Caesarean uterine scar and diagnosis of dehiscence. Ultrasound Obstet Gynecol 1994; 4: 151-3.

[22] Markos F, Ramin KD, Twickler DM, Barron J, Ramin SM. Ultrasonographic diagnosis of uterine rent at 33 weeks' gestation with history of curettage. Am J Obstet Gynecol 1995; 172: 224-6.

[23] Catanzarite VA, Mehalek KE, Wachtel T, Westbrook C. Sonographic diagnosis of traumatic and later recurrent uterine rupture. Am J Perinatol 1996; 13: 177-80.

[24] Bujold E, Jastrow N, Simoneau J, Brunet S, Gauthier RJ. Prediction of complete uterine rupture by sonographic evaluation of the lower uterine segment. Am J Obstet 
Gynecol 2009; 201: 320.e1-6.

[25] Nomizo M, Baba T, Suzuki A, Yamanishi M, Yamaguchi A, Kakui K, et al. Uterine diffuse leiomyomatosis arising in two sisters. Adv Obstet Gynecol 2013; 65: $40-5$.

\section{Figure Legends}

Figure 1. Serial ultrasound and MRI images.

(A) Ultrasound images of the upper, middle, and lower part of the uterus. A large herniated amniotic sac measuring 70 x $45 \mathrm{~mm}$ was protruding into the maternal abdominal cavity at the uterine fundus (left). Reduced amniotic fluid around the foetus (middle), and short cervical length with funnelling (right) were observed. (B-D) T2-weighted magnetic resonance sagittal (left) and coronal (right) images of uterus at 18, 22, and 26 weeks of gestation. Numerous fibroids were located in bilateral sides of the uterine cavity, and lower uterine segment was progressively overstretched as early as 26 weeks' gestation. (E) A scheme showing that the uterine wall is disproportionally overstretched due to decreased ability to stretch in the middle part of uterine wall. (F) Further overextended lower uterine segment at 29 
weeks' gestation. (G) An abdominal ultrasound image of thin lower uterine segment muscular thickness measuring $1.3 \mathrm{~mm}$.

Figure 2. Intraoperative view and a follow-up MRI image three months postpartum.

(A) Extended lower uterine segment at operation. A bulging amniotic sac was seen by slightly cutting the lower uterine segment (right). (B) After delivery, vertical midline hollow traces of previous uterine incision for myomectomy. (C) T2-weighted magnetic resonance sagittal image of uterus three months postpartum showing thin myometrium of the uterine fundus.

\section{Legend for Supplemental Figure}

Supplementary Figure 1. Diffuse uterine leiomyomatosis.

(A) T2-weighted sagittal magnetic resonance image for diffuse uterine leiomyomatosis and (B) intraoperative view of myomectomy. Abdominal enucleation was performed through a vertical incision from the anterior to posterior wall via the uterine fundus. 
Table 1. Literature review of a herniated amniotic sac out of overstretched uterine wall before 34 weeks' gestation.

CS; caesarean section 


\begin{tabular}{|c|c|c|c|c|c|c|c|c|c|c|}
\hline $\begin{array}{l}\text { Cas } \\
\mathrm{e} \\
\text { ne } \\
\end{array}$ & $\begin{array}{c}\text { Age } \\
\text { (years) }\end{array}$ & $\begin{array}{c}\text { Gravit } \\
\text { y/Pari } \\
\text { tv }\end{array}$ & $\begin{array}{c}\text { Onset of } \\
\text { symptom (wks) }\end{array}$ & Symptom at diagnosis & Underlying cause & $\begin{array}{l}\text { Location of } \\
\text { uterine defect }\end{array}$ & Management & Outcome & $\begin{array}{c}\text { Author } \\
\text { (reference) }\end{array}$ & Year \\
\hline 1 & 25 & $3 / 0$ & 10 & Abdominal pain & $\begin{array}{l}\text { Utterine perforation following curettage and subsequent } \\
\text { uterine rupture }\end{array}$ & Fundus & Expectant & $\begin{array}{l}\text { CS due to acute abdominal pain (32w), and subsequent caesarean } \\
\text { hysterectomy for placenta peroreta }\end{array}$ & Deka D [1] & 2011 \\
\hline 2 & 39 & $4 / 3$ & 17 & Sudden lower abdominal pain & Uterine perforation following curettage & Fundus & Expectant & CS due to fetal tachycarda vith recurrent deep variable decelerations (33w) & Oyelese $Y[2]$ & 2003 \\
\hline 3 & 34 & $4 / 3$ & 20 & Abdominal pain & None & Fundus & Expectant & CS due to severe variable decelerations in fetal heart rate $(29 \mathrm{w})$ & Cotton DB [3] & 1982 \\
\hline 4 & 32 & $4 / 2$ & 20 & Vaginal bleeding and uterine cramps & Previous cS & Lower uterine segment & Expectant & CS due to variable decelerations in fetal heart rate( $(31 w)$ & Hamar BD [4] & 2003 \\
\hline 5 & 27 & $3 / 1$ & 24 & None & $\begin{array}{l}\text { Previous CS (irverted Tincision) with a subsequent } \\
\text { currettage for retained placenta }\end{array}$ & Fundus & Expectant & $\begin{array}{l}\text { CS due to significant uterine tenderness ( } 27 \mathrm{w} \text { ), and subsequent } \\
\text { hysterectomy for massive haemorrhage due to placental increta }\end{array}$ & Hunter $T\lrcorner[5]$ & 2009 \\
\hline 6 & 30 & $3 / 2$ & 25 & Lower abdominal pain & Two previous CS & Lowor uterine segment & Expoctant & CS due to acute suprapubic pain and docelerations in fetal hoart rate (32w) & Taipalo P [6] & 2005 \\
\hline 7 & 25 & $5 / 3$ & 27 & Abdominal pain & Previous CS (26w) & Anterior wall & Expectant & CS due to uterine rupture (30w) & Rabinowitz R [7] & 2006 \\
\hline 8 & N/A & $2 / 1$ & 33 & Lower abdominal pain & Previous CS & Lower uterine segment & Expectant & CS due to increased pain (34w) & Taipale P [6] & 2005 \\
\hline 9 & 32 & $2 / 1$ & 6 & Uterine cramping & Uterine perforation following curettage & Fundus & Surgical repair (9w) & CS due to preterm labor (33w) & Cheng PJ [8] & 2003 \\
\hline 10 & 20 & $7 / 0$ & 13 & $\begin{array}{l}\text { Suddon abdominal pain and vaginal } \\
\text { bleeding }\end{array}$ & $\begin{array}{l}\text { Provious laparoscopic cormual resection for an inteatinal } \\
\text { preegnancy. and twin pregnancy }\end{array}$ & Fundus & $\begin{array}{l}\text { Surgical repair } \\
(13 w)\end{array}$ & OS due to preterm labor $(30 \mathrm{w})$ & Liao oy [0] & 2009 \\
\hline 11 & 27 & $5 / 3$ & 13 & $\begin{array}{l}\text { Lower abdominal cramping and } \\
\text { vaginal bleeding }\end{array}$ & Three previous OS & Lower uterine segment & Termination & Hysterectomy (15w) & $\begin{array}{c}\text { Hamrick-Tumer JE } \\
{[10]}\end{array}$ & 1995 \\
\hline 12 & 27 & $5 / 2$ & 19 & None & Two previous cS & Lower uterine segment & Termination & Terminaiton with elassical hysterotomy (21w) & Zuckerwise LC [11] & 2011 \\
\hline 13 & 30 & $3 / 1$ & 19 & None & Uterine perforation following curettage & Fundus & $\begin{array}{c}\begin{array}{c}\text { Surgical repair } \\
(20 w)\end{array} \\
\end{array}$ & $\operatorname{cs}(36 w)$ & Fuiji T [12] & 2000 \\
\hline 14 & 29 & $2 / 0$ & 21 & None & Previous laparoscopic myomectomy, and twin pregnaney & Fundus & Termination & 21w terminaiton & Chou MM [13] & 2007 \\
\hline 15 & 31 & $3 / 1$ & 22 & None & Previous CS & Lower uterine segment & $\begin{array}{c}\text { Surgical repair } \\
(26 \mathrm{w})\end{array}$ & CS due to spontaneous labor (28w) & Gorthi S [14] & 2009 \\
\hline 16 & 30 & $3 / 2$ & 23 & Abdominal discomfort & Amniocentesis (22w) & Fundus & Termination & CS due to vaginal bleeding and proeressive lower abdominal pain (23w) & Jo YS [15] & 2012 \\
\hline 17 & $\begin{array}{l}\text { late } \\
\text { nnc }\end{array}$ & $3 / 1$ & 26 & Acute abdominal pain & Previous cs & Lower uterine segment & Termination & CS due to worsening pain and decelerations in fetal heart rate (26w) & Youngs DJ [16] & 2004 \\
\hline 18 & 29 & $1 / 0$ & 26 & $\begin{array}{l}\text { Abdominal pain, naussea, and } \\
\text { vomiting }\end{array}$ & None & Fundus & $\begin{array}{l}\text { Surgical repair } \\
(26 w)\end{array}$ & $\operatorname{cs}(37 w)$ & Chen FP [17] & 2007 \\
\hline 19 & 29 & $5 / 1$ & 28 & Suprapubic pelvic pain & High transverse CS & Anterior wall & Termination & CS due to variable fetal haart decelerations (2Bw) & Kushnir O [18] & 1990 \\
\hline 20 & 34 & $7 / 3$ & 28 & Vague abdominal pain & $\begin{array}{l}\text { Previous cornual uterine rupture following salpingectomy for } \\
\text { ectopic pregnancy }\end{array}$ & Fundus & Termination & $\operatorname{cs~(28w)~and~subsequent~supravaginal~hysterectomy~}$ & van Aphen M [19] & 1995 \\
\hline 21 & 30 & $1 / 0$ & 29 & Lower abdominal pain & Laaaroscopic myomectomy & Posterior wall & Termination & $\begin{array}{l}\text { CS due to increasing abdominal pain and a low- grade temperature of } 38^{\circ} \mathrm{C} \\
\text { (29w) }\end{array}$ & Hasbarken U [20] & 2002 \\
\hline 22 & 26 & $3 / 1$ & 31 & Acute upper abdominal pain & Classical cs & $\begin{array}{l}\text { Uoper end of the } \\
\text { previous uterine scar }\end{array}$ & Termination & $\operatorname{cs}(3 \mid w)$ & Avrech OM [21] & 1994 \\
\hline 23 & 30 & $6 / 3$ & 33 & $\begin{array}{l}\text { Decreased fetal movement. and } \\
\text { intermittent abdominal pain }\end{array}$ & Uterine perforation following curettage & Fundus & Termination & $\operatorname{cs}(33 \mathrm{w})$ & Markos $\mathrm{F}$ [22] & 1995 \\
\hline 24 & $\mathrm{~N} / \mathrm{A}$ & $5 / 3$ & 33 & $\begin{array}{l}\text { Abdominal cramps and upper } \\
\text { abdominal pain }\end{array}$ & $\begin{array}{l}\text { Previous traumatic transverse fundal uterine rupture, Twin } \\
\text { gestation }\end{array}$ & Fundus & Termination & $\operatorname{cs}(33 w)$ & Catanzarite VA [23] & 1996 \\
\hline 25 & 38 & $1 / 0$ & 18 & None & $\begin{array}{l}\text { Previous myamectomy through a vertical incisison from } \\
\text { anterior to posterior wall via uterine fundus }\end{array}$ & Fundus & Expectant & $\begin{array}{l}\text { CS dua to lower uterine segment thinning and a vague lower abdominal } \\
\text { disoomfort (30w) }\end{array}$ & Present case & 2013 \\
\hline
\end{tabular}


Figure 1
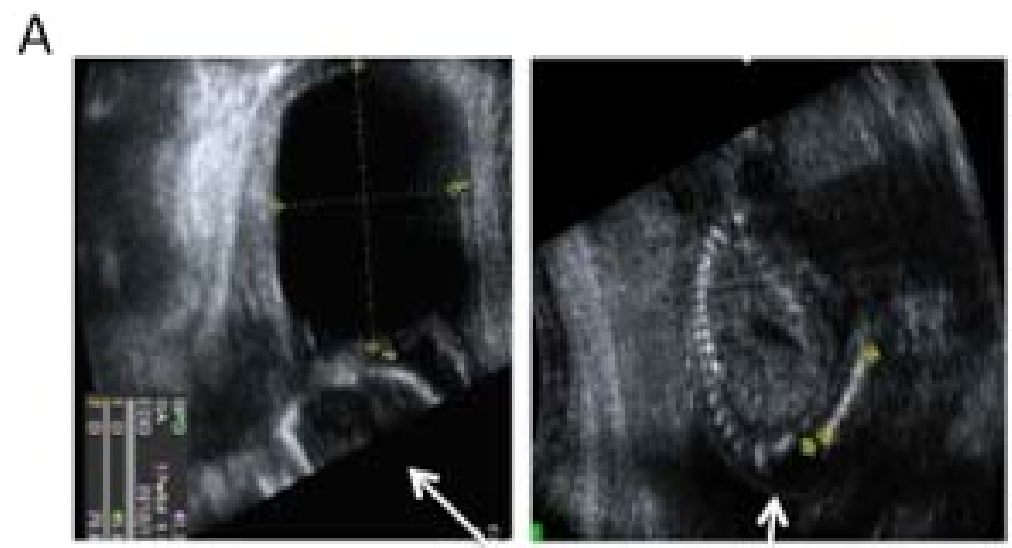

B
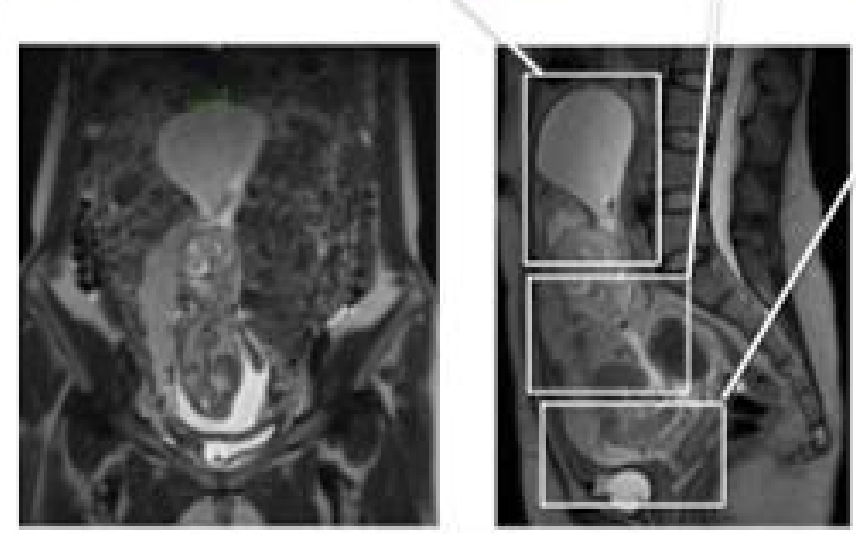

D
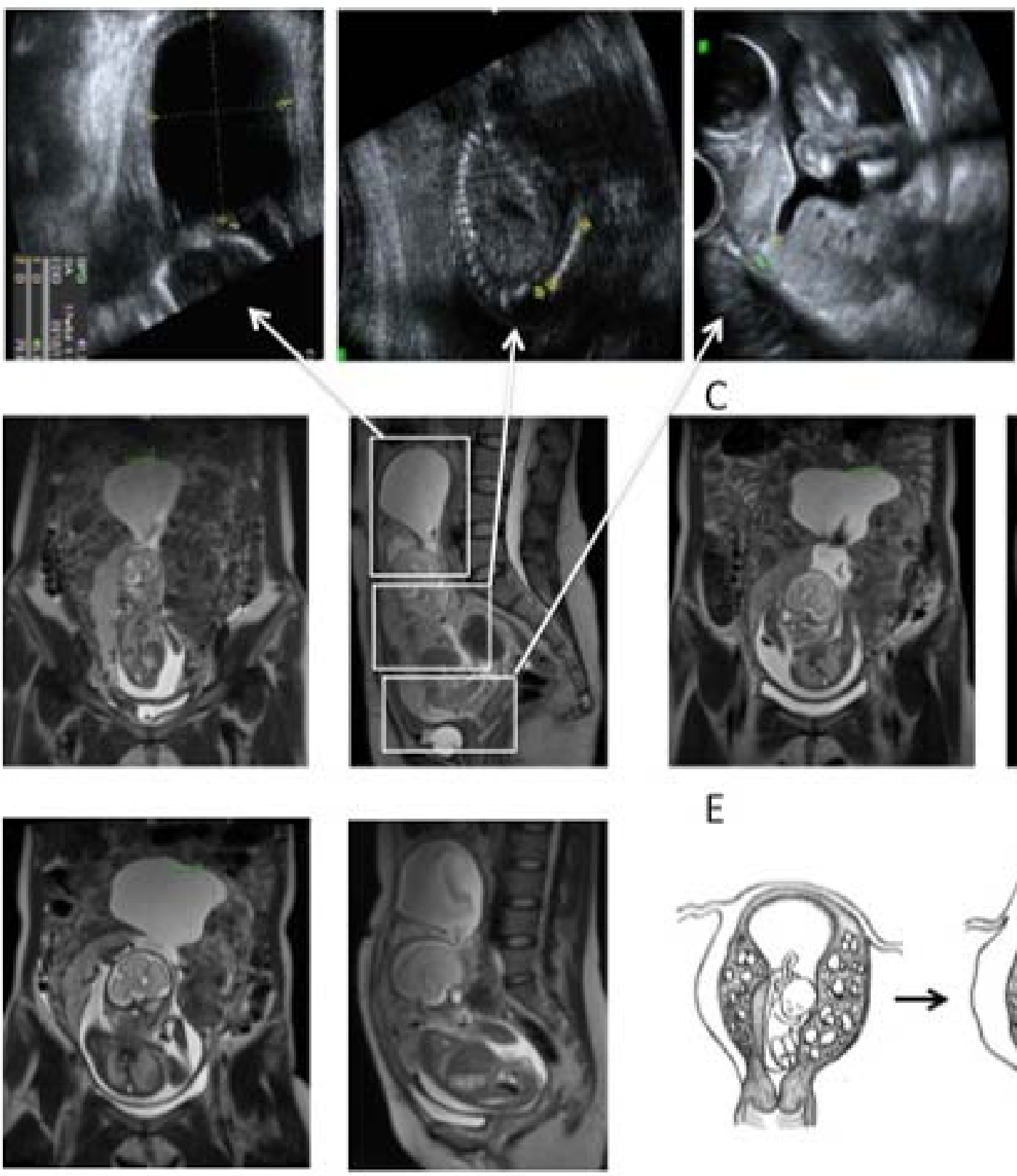

C
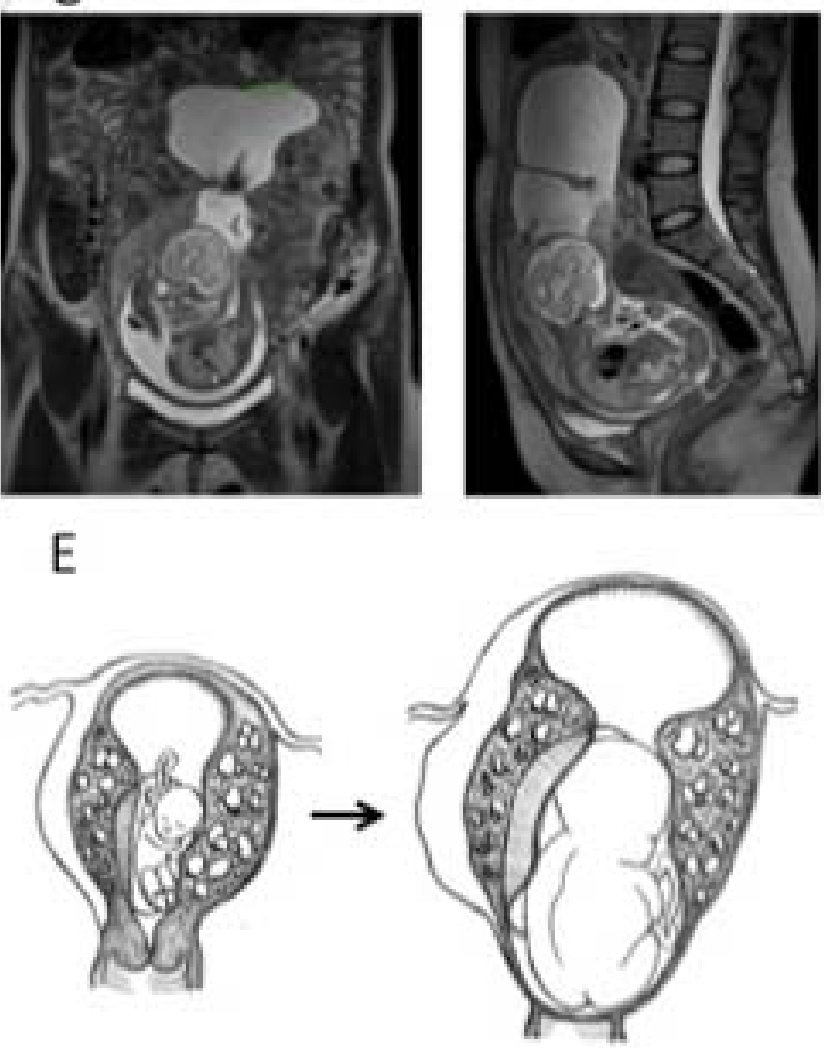

F
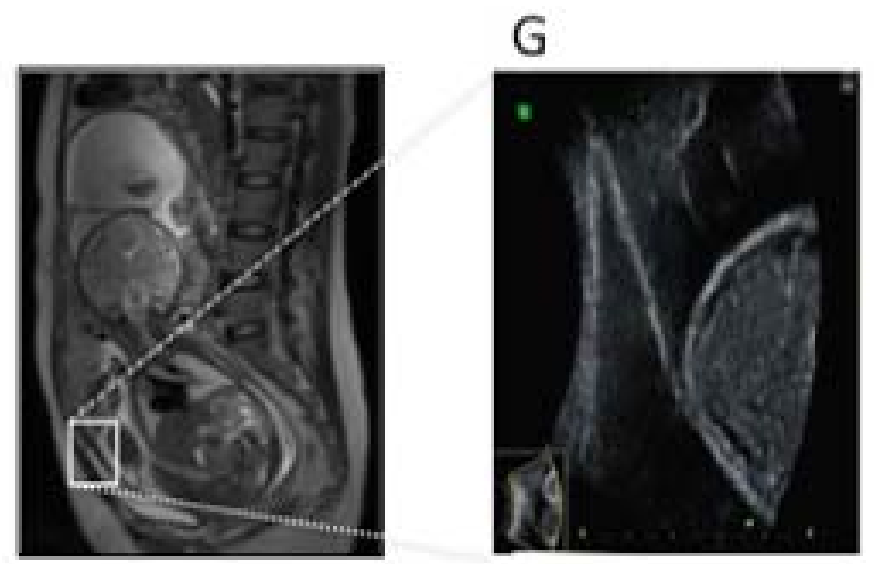
Figure 2

A
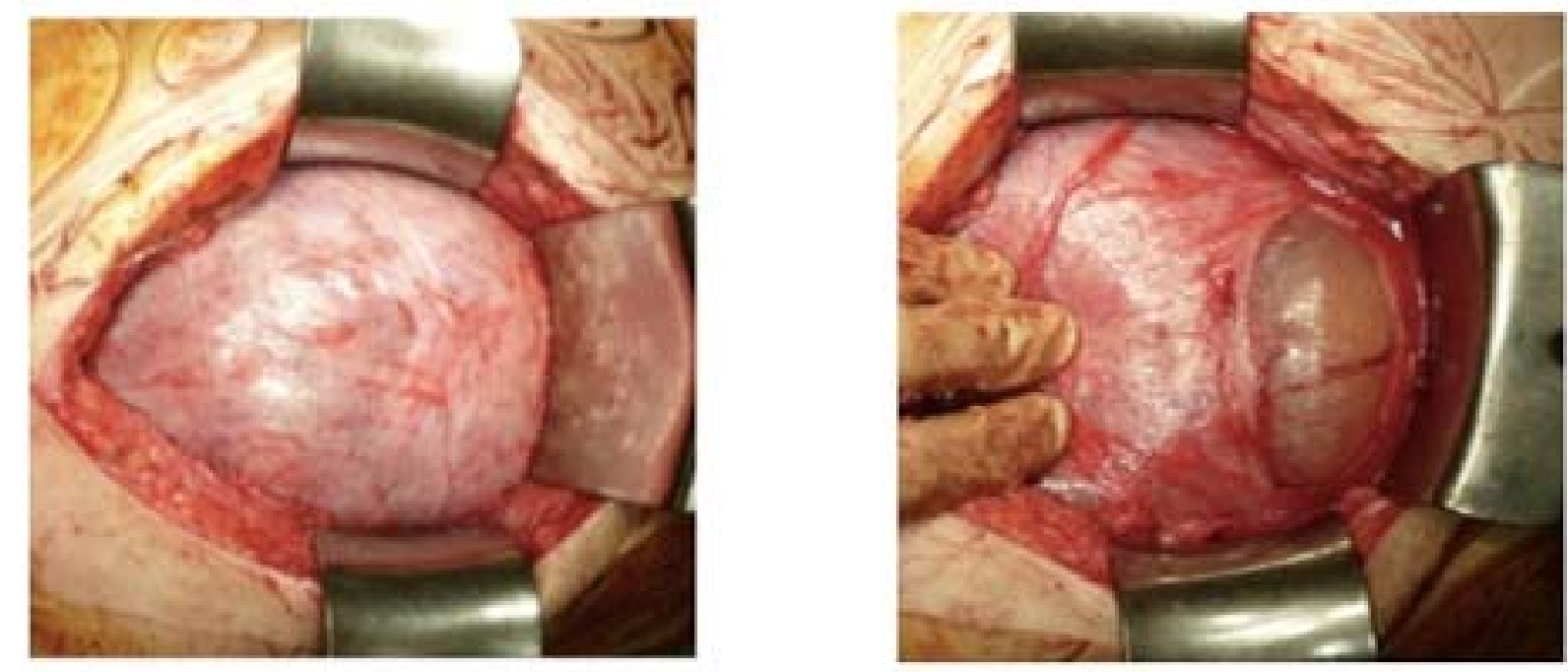

B

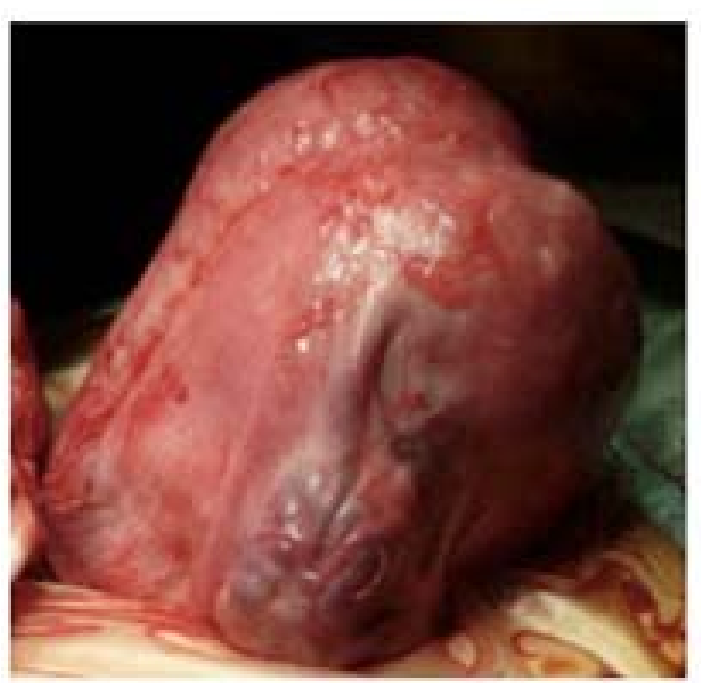

C

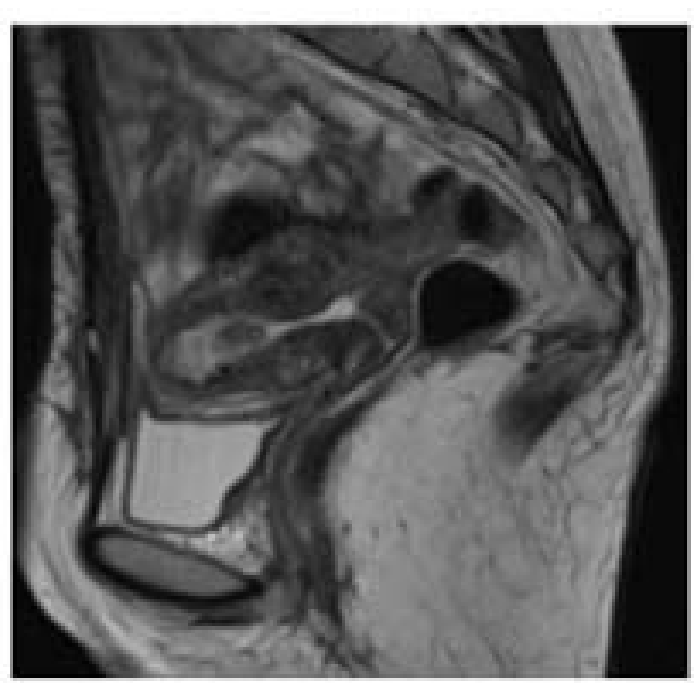

